\title{
Climate change and summer thermal comfort in China
}

Qinqin Konga,b, Jingyun Zheng ${ }^{\mathrm{a}}$, Hayley J. Fowler ${ }^{\mathrm{b}}$, Quansheng Ge ${ }^{\mathrm{a}}$, Jianchao Xi ${ }^{\mathrm{a}}$

a. Key Laboratory of Land Surface Pattern and Simulation, Institute of Geographical Sciences and Natural Resources Research, Chinese Academy of Sciences, Beijing, 100101, China.

b. School of Civil Engineering and Geosciences, Newcastle University, Newcastle upon Tyne, UK

* Authors for correspondence: Qinqin Kong

* Key Laboratory of Land Surface Pattern and Simulation, Institute of Geographical Sciences and Natural Resources Research, Chinese Academy of Sciences, Beijing 100101, China

Qinqin Kong

Tel: +8618810329106

E-mail: kongqq@igsnrr.ac.cn

\section{Acknowledgement}

Qinqin Kong is funded by the China Scholarship Council (No.201604910868); Jingyun Zheng is funded by the National Natural Science Foundation of China (Grant No. 41671036); Hayley J. Fowler is funded by the European Research Council Grant, INTENSE (ERC-2013-CoG-617329). 


\section{Climate change and summer thermal comfort in China}

Abstract: Heat escape motivated travel, called 'sunbird' tourism, has become increasingly important with global warming and associated urban heat island effects. This study proposes a new method based on defining 'comfortable' calendar days, to identify regions thermally suitable for 'sunbird' tourism (namely northern Northeast China, eastern Inner Mongolia Plateau, northern Xinjiang Province, eastern Qinghai-Tibet Plateau, and Yungui Plateau) and their comfortable periods in China. From 1961-1990 to 1987-2016, comfortable periods have extended by 5 to over 20 days in eastern Qinghai-Tibet Plateau and parts of Yungui Plateau, but shortened by 5 to over 20 days in northern Northeast China and eastern Inner Mongolia Plateau, corresponding to 9 and 21 locations respectively becoming suitable and no longer suitable for 'sunbird' tourism. Moreover, comfortable periods are now much earlier in the eastern Inner Mongolia Plateau, and have dramatically altered in terms of their temporal distribution over the eastern Qinghai-Tibet Plateau. Finally, we discuss the implications for tourism.

Keywords: Universal Thermal Climate Index; climate change; summer thermal comfort; 'sunbird' tourism;

\section{China}

\section{Introduction}

Tourism is closely linked to weather and climate. Climate, on the one hand, forms an important component of the geographical space that tourism activities are built on, and on the other, can be a tourism resource or attraction in itself (Gómez Martín 2005). Tourism climatologists describe climate through thermal, physical (rain, snow wind, air quality), and aesthetical (sunshine, cloud cover, fog) facets (de Freitas 1990; de Freitas 2003). The thermal facet, also the focus of this study, concerns the ambient circumstances' influence on tourists' thermal perceptions, and is strongly subject to climate change (Batista et al. 2016; Cheung and Hart 2014; Li and Chi 2014). 
There is a large amount of literature studying the effects of climate change on tourism. By altering the length and quality of tourism seasons, climate change can affect the attractiveness of tourism destinations. In Europe, popular destinations will shift northward and upward under an arbitrary $1{ }^{\circ} \mathrm{C}$ warming scenario (Giannakopoulos et al. 2011; Hamilton et al. 2005). The Tourism Climate Index, a measure of climate suitability, mainly for sightseeing and nature-based tourism (Mieczkowski 1985), is expected to improve in western and northern Europe (Amelung and Viner 2006; Hanson et al. 2006; Nicholls and Amelung 2008). For destinations in south and southeast Europe, such as the Mediterranean, the shoulder seasons (spring and autumn) are becoming increasingly attractive, with the traditional peak season (summer) becoming less attractive (Amelung and Moreno 2012; Amelung et al. 2007; Amelung and Viner 2006; Amengual et al. 2014; Hamilton et al. 2005; Hein et al. 2009; Nicholls and Amelung 2008; Rutty and Scott 2010). Subsequent impacts can be generated upon various facets pertinent to tourism operation, including the design of tourism products, route planning, infrastructure construction (new accommodation, outdoor shelters, etc.), local tourism-related services, etc. (Lemesios et al. 2016; Nicholls and Amelung 2008).

Travels motivated by escaping summer heat, called 'sunbird' tourism (Scott et al. 2004), have become increasingly important during recent decades under the combined impacts of global warming and exacerbated urban heat island effects (Yang et al. 2016). The thermally comfortable climate that these travellers seek is sensitive to climate change, since the warming trend may make the climate not comfortable anymore, or shorten the comfortable period. Identifying the spatial and temporal distribution of thermal comfort is helpful for optimizing the layout of destinations and for tourists making travel plans. Revealing changes in thermal comfort can contribute to better adaptation decisions for the tourism sectors.

Currently, only a few studies have been focused on examining the spatial distribution or temporal change in summertime thermal comfort. Scott et al. (2004) investigated the distribution and changes of tourism climate 
potential in North America. They identified the summer peak (with favourable climate in summer) destinations and estimated their spatial migration under different scenarios. The overall finding is a northward shift of summer peak zones, which, according to the authors, implies a continued growth in the 'sunbird' tourism market characterized by southern USA residents travelling to more northern locations. Grillakis et al. (2016) evaluated the responses of summertime climate comfort in Europe to a $2{ }^{\circ} \mathrm{C}$ global warming, revealing an improvement in central and northern Europe and a reduction in adjacent Mediterranean areas due to increasing daytime temperature (Grillakis et al. 2016). However, the concept of climate comfort in the above studies reflects a combined effect of various factors including temperature, humidity, precipitation, sunshine duration and wind speed (temperature and humidity together were considered as a representation of thermal conditions), rather than focusing only on the thermal facet.

In China, the seasonal human thermal climatology has been described. Ge et al. (2017) mapped the seasonal value and frequencies of the Universal Thermal Climate Index (UTCI), one of the state-of-art thermal indices. They identified areas with no thermal stress in a high frequency. Seasonal maps of physiologically equivalent temperature in eastern China and Taiwan have also been provided (Lin and Matzarakis 2011). Other summerfocused studies have tried to identify areas thermally suitable for 'sunbird' tourism by examining monthly or tenday average UTCI values (Chen et al. 2015; Yang et al. 2016). However, none of them have performed detailed analyses about which area is comfortable during which specific period, yet this information is crucial for tourists planning their travels. Moreover, results based on monthly or ten-day average UTCI values may sometimes mislead readers, due to probable large diurnal variations in climate factors which is the case in vast inland areas of western China (Wang and Li 2007). For example, a day with hot day-time and cold night-time temperatures may be inappropriately regarded as comfortable. In addition, temporal changes in summer thermal comfort in 
China are still unaddressed. Questions like "what are the effects of climate change on thermal comfort?", and "has any destination become less or more thermally favourable for 'sunbird' tourism?" remain unanswered.

Therefore, the present study, using the UTCI and meteorological observations, attempts to investigate both the spatial distribution and temporal variations of summer thermal comfort in China. The aim is to identify potential regions thermally suitable for 'sunbird' tourism and their comfortable periods, and the associated changes from 1961-1990 to 1987-2016.

\section{Data and methods}

\subsection{Data sources}

In this study, we used daily meteorological observations for summer (JJA) during 1961-2016. The parameters include daily mean, maximum and minimum air and surface temperature, relative humidity, wind speed, and sunshine duration. To eliminate the effects of missing data, the following treatments were applied: for a certain station, any year with any parameter showing missing data of more than $10 \%$ or at least 5-consecutive days missing was removed; stations with over 5 years being removed were discarded; then we replaced the remaining missing values with averages of the nearest four observations. Eventually, a total of 462 stations (Fig. 1) were used for the subsequent analyses. Also shown in Figure 1 are China's topography and geographical features that mentioned in this study. 


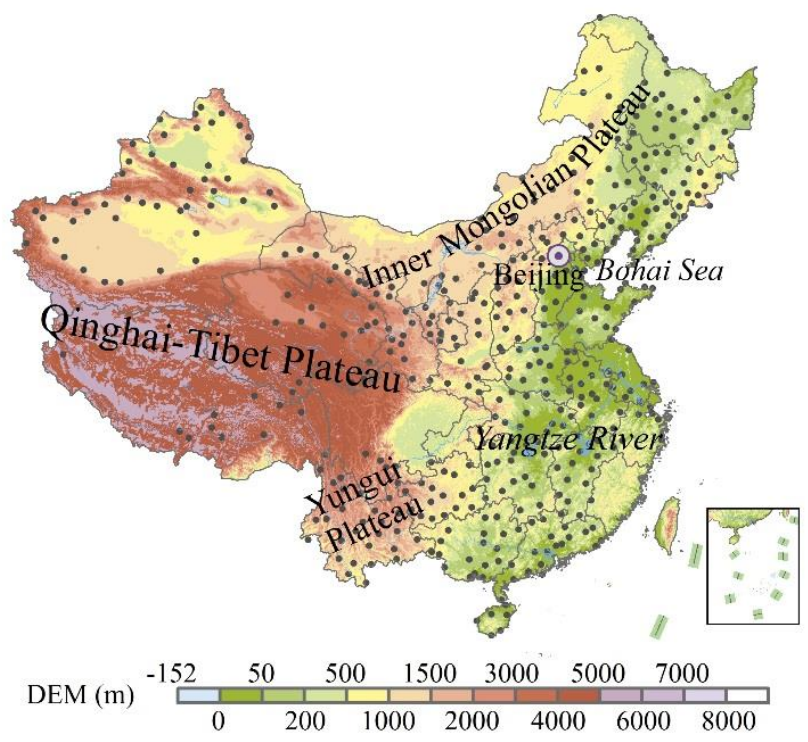

Fig. 1 Meteorological stations and topography of China, with geographical features mentioned in this study marked.

\subsection{Universal Thermal Climate Index}

The UTCI, integrating Fiala et al.'s (2001, 2012) (Fiala et al. 2012; Fiala et al. 2001) multi-node thermoregulation model and an adaptive clothing model (Havenith et al. 2012), aims to measure human physiological response to ambient thermal environment. It is defined as the equivalent temperature that would elicit the same dynamic physiological response under a set of reference conditions (Bröde et al. 2012; Jendritzky et al. 2012). Table 1 summarizes its thermal stress assessment scales according to the modelled physiological response (Bröde et al. 2012). Compared with other indices, the UTCI is applicable in different climates, sensitive to ambient factors' changes, and good at describing temporal variations in thermal conditions (Blazejczyk et al. 2012).

Table 1 UTCI equivalent temperatures categorized in terms of thermal stress (Bröde et al. 2012)

\begin{tabular}{llll}
\hline UTCI range $\left({ }^{\circ} \mathrm{C}\right)$ & Stress category & UTCI range $\left({ }^{\circ} \mathrm{C}\right)$ & Stress category \\
\hline$<-40$ & Extreme cold stress & $9-26$ & No thermal stress \\
-40 to -27 & Very strong cold stress & $26-32$ & Moderate heat stress \\
\hline
\end{tabular}




\begin{tabular}{|c|c|c|c|}
\hline-27 to -13 & Strong cold stress & $32-38$ & Strong heat stress \\
\hline$-13-0$ & Moderate cold stress & $38-46$ & Very strong heat stress \\
\hline $0-9$ & Slight cold stress & $\geq 46$ & Extreme heat stress \\
\hline
\end{tabular}

The simple UTCI calculation method was employed, based on a six-order regression of UTCI to four meteorological variables: 2-m air temperature $\left(\mathrm{Ta},{ }^{\circ} \mathrm{C}\right), 10-\mathrm{m}$ wind speed $(\mathrm{V}, \mathrm{m} / \mathrm{s})$, vapor pressure $(e, \mathrm{hPa})$ and mean radiant temperature $\left(\operatorname{Tmrt}^{\circ}{ }^{\circ} \mathrm{C}\right)($ Eq. 1) (Bröde et al. 2012).

UTCI-Ta $=f(T a, V, e, T m r t-T a)$

The vapor pressure can be computed as follows:

$$
e=(6.112 \cdot \exp ((17.67 T a) /(T a+243.5))) \cdot(R H / 100)
$$

Where $R H(\%)$ is relative humidity. For the mean radiant temperature, the formulation is:

$$
T m r t=\left((\text { Rprim }+0.5 L g+0.5 L a) /\left(0.95 \times 5.667 \times 10^{-8}\right)\right)^{1 / 4}-273
$$

$\operatorname{Rprim}\left(\mathrm{W} / \mathrm{m}^{2}\right)$ refers to the solar radiation absorbed by a nude man; $L g$ and $L a$ denote the long-wave radiation flux densities emitted by the surface and atmosphere respectively.

$$
\begin{aligned}
& L g=5.5 \times 10^{-8}(273+T g)^{4} \\
& L a=5.5 \times 10^{-8}(273+T a)^{4}\left(0.82-0.25 \times 10^{(-0.094 \times 0.75 e)}\right)
\end{aligned}
$$

Here, $\operatorname{Tg}\left({ }^{\circ} \mathrm{C}\right)$ is surface temperature.

Our analyses require calculating not only the mean but also the maximum and minimum UTCI values (hereinafter referred to as UImean, UImax and UImin), with daily mean, maximum and minimum air and surface temperature being employed respectively. Whereas, average wind speed and vapor pressure were used consistently. The most significant difference among these three cases lies in the calculation of Rprim. For the minimum case, Rprim 
equals zero since we assume the lowest UTCI values occur during night. The highest UTCI values are assumed to take place at 14:00 in solar time. Then, Rprim can be computed through the SolAlt model (Błazejczyk 2004). The total cloud cover in the SolAlt model can be approximated by subtracting the percent of possible sunshine from 100\% (Essa and Etman 2004), which has been proved reasonable by Douglas (1977). As for UImean, Rprim was calculated via the daily global solar radiation received by the surface $\left(G, \mathrm{MJ} \mathrm{m}^{-2}\right.$ day $\left.^{-1}\right)($ Eq. 7$)$ which can be estimated through a revised version of Angström model (Eq. 6) (Rensheng et al. 2006).

$G=E \cdot\left(0.280-0.141 \cos (\varphi)+2.60 \times 10^{-5} H\right)+0.542 \frac{s d}{p s d}$

$$
\operatorname{Rprim}=a c \cdot\left(G \cdot 10^{6}\right) /(24 \times 3600)
$$

Where $E\left(\mathrm{MJ} \mathrm{m}^{-2}\right.$ day $\left.^{-1}\right)$ is the daily extra-terrestrial solar radiation (lqbal 1983); $\varphi$ and $H(\mathrm{~m})$ are the latitude and altitude respectively; $s d(\mathrm{~h})$ and $p s d(\mathrm{~h})$ refer to the actual and possible sunshine duration; $a c$ is absorption coefficient of solar radiation for human body surface (standard value 0.7).

\subsection{Assessment of thermal suitability for 'sunbird' tourism}

A series of definitions were introduced to assess the thermal suitability for 'sunbird' tourism at each station. A certain calendar day from June to August during a period, say 1961-2016, will be considered as comfortable if both the long-term average value and over half of daily observations range from $9{ }^{\circ} \mathrm{C}$ to $26{ }^{\circ} \mathrm{C}$ for UImean, fall below $32{ }^{\circ} \mathrm{C}$ for UImax, and exceed $0{ }^{\circ} \mathrm{C}$ for UImin. A hot calendar day should show frequencies of UImean $>26$ ${ }^{\circ} \mathrm{C}$ of more than $70 \%$, and UImax $>32{ }^{\circ} \mathrm{C}$ ( or $38^{\circ} \mathrm{C}$ ) of more than $70 \%$ (or 30\%). The ensemble of summertime comfortable days constitutes the comfortable period. A station thermally suitable for 'sunbird' tourism should, on the one hand, show a comfortable period length (CPL) of no less than 50 days, and on the other, possess at least 20-consecutive comfortable days. The thermal suitability can be assessed within different temporal contexts. In 
order to detect changes in thermal comfort, the study period was divided into two 30-year sub-periods, namely 1961-1990 and 1987-2016 between which thermal conditions were compared.

\section{Results}

\subsection{Climotology of summer thermal comfort during 1961-2016}

Long-term summer average UImean, UImax and UImin from 1961 to 2016 are presented in Figure 2a-c, showing latitudinal distributions in eastern China. UImean (UImax) ranges from $9{ }^{\circ} \mathrm{C}$ to $26^{\circ} \mathrm{C}\left(26^{\circ} \mathrm{C}\right.$ to $\left.32^{\circ} \mathrm{C}\right)$ in northern Northeast China and eastern Inner Mongolia Plateau, $32^{\circ} \mathrm{C}$ to $38^{\circ} \mathrm{C}\left(38^{\circ} \mathrm{C}\right.$ to $\left.46^{\circ} \mathrm{C}\right)$ south to Yangtze River, and $26^{\circ} \mathrm{C}$ to $32{ }^{\circ} \mathrm{C}\left(32{ }^{\circ} \mathrm{C}\right.$ to $\left.38^{\circ} \mathrm{C}\right)$ in the remaining areas. UImin, in comparison, is universally between $9^{\circ} \mathrm{C}$ and 26 ${ }^{\circ} \mathrm{C}$. CPLs generally exceed 30 days in northern Northeast China, the eastern Inner Mongolia Plateau, and the northern Xinjiang Province, and exceed 70 days in parts of eastern Qinghai-Tibet Plateau and Yungui Plateau. These regions also appear to be thermally suitable for 'sunbird' tourism (Fig. 3a). However, only at one station is the number of comfortable days over 50 in total but below 20 consecutively, indicating that the requirement for 20-consecutive comfortable days is actually meaningless. Additionally, restrictions on daily maximum and minimum UTCI values were removed to see the effects of atmospheric diurnal variation, and we found 19 more thermally suitable stations mainly distributed on the Inner Mongolia Plateau and the Qinghai-Tibet Plateau where the diurnal temperature range is relatively large (Fig. 3b) (Wang and Li 2007). 

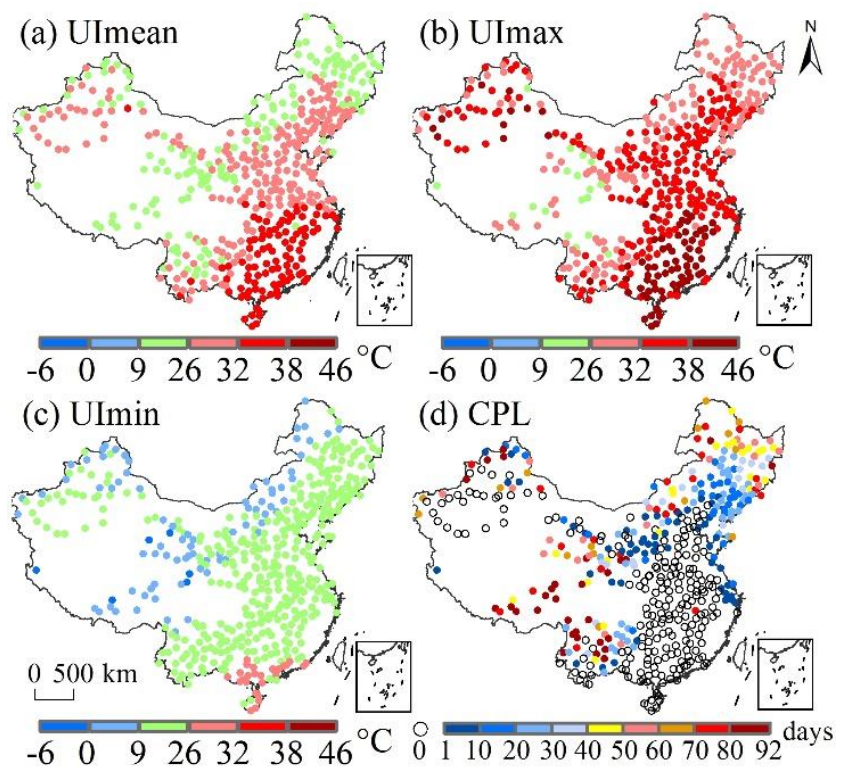

Fig. 2 Long-term summer average UImean (a), UImax (b) and UImin (c), and CPL(d) in China during 1961-2016.

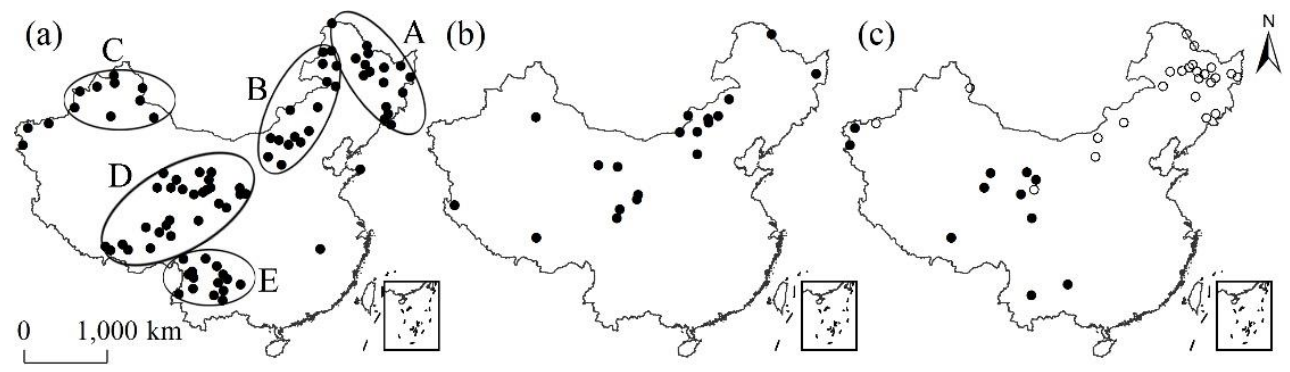

Fig. 3 Stations thermally suitable for 'sunbird' toursim within the context of 1961-2016 (a); the ellipses A, B, C,

D, and E incorporate stations over northern Northeast China, eastern Inner Mongolia Plateau, northern Xinjiang

Province, eastern Qinghai-Tibet Plateau, and Yungui Plateau respectively; newly added suitable stations after removing restrictions on daily maximum and minimum UTCI values (b); newly added (black dots) and removed (circles) suitable stations from 1961-1990 to 1987-2016 (c);

Furthermore, it is important for tourists to know which period is comfortable. Although it is easy to locate comfortable days for every single station, we still extend the definitions of "comfortable" and "hot" from daily to ten-day scale for the convenience of national-scale mapping (Fig. 4). Comfortable climate occurs in June and the last two ten-day intervals of August in northern Northeast China, lasts from the second ten-day interval of June to August on the eastern Inner Mongolia Plateau, and persists for the whole summer in the northern Xinjiang 
Province, eastern Qinghai-Tibet Plateau and the Yungui Plateau. Additionally, the southern two-thirds of eastern

China, also the countries' most densely-populated area, suffers hot conditions throughout summer, indicating large potential demands for travelling to escape the extreme heat.
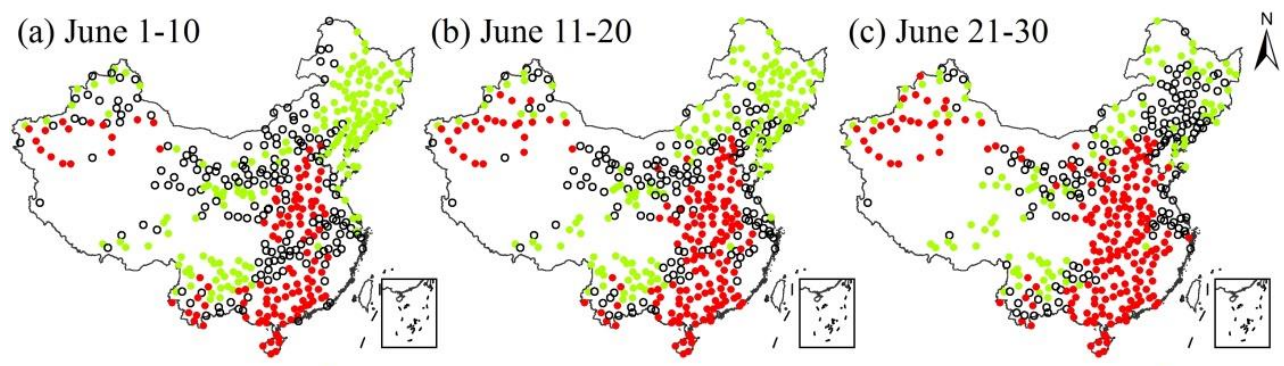

(d) July 1-10

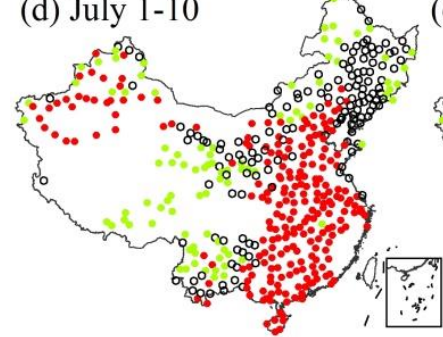

(e) July 11-20

(f) July 21-31

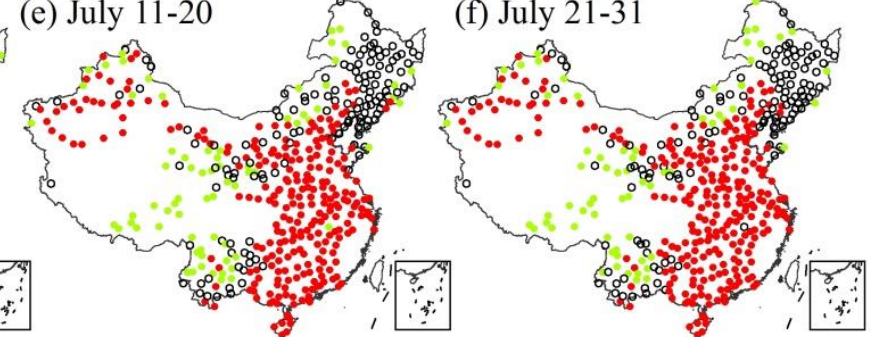

(g) August 1-10

(h) August 11-20

(i) August 21-31
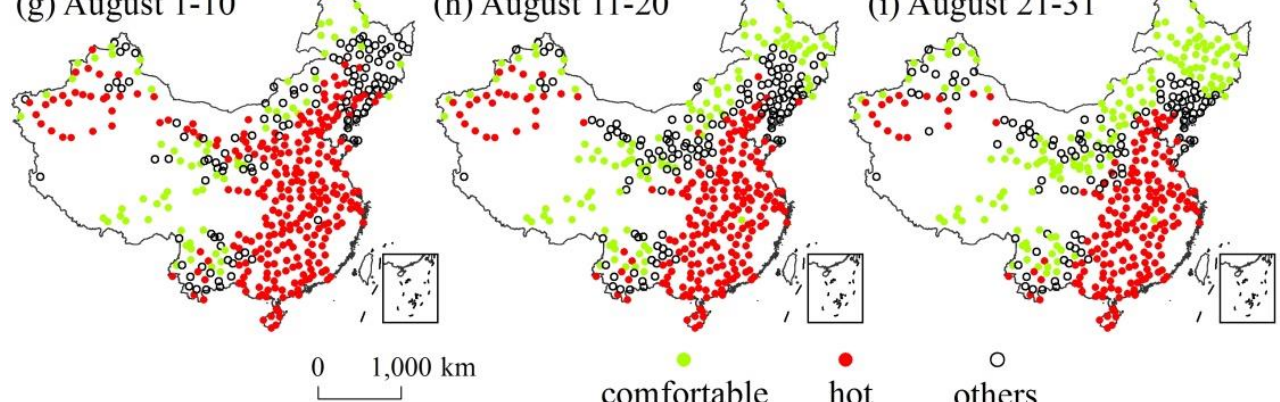

comfortable hot others

Fig. 4 Thermal conditions for each ten-day interval of summer in China during 1961-2016.

\subsection{Changes in summer thermal condition from 1961-1990 to 1987-2016}

The study period was divided into two 30-year subperiods (1961-1990 and 1987-2016), and changes in thermal conditions between them were investigated. Summer average UImax decreases in the southern two-thirds of eastern China and significantly increases (0.01 significance level without special mention) in remaining areas;

UImin significantly increases nationwide. Both of them show more warming over northern China, yet with substantially larger magnitudes of increase for UImin (over $3^{\circ} \mathrm{C}$ increases at some stations). UImean basically reflects a compromise between UImax and UImin in terms of change characteristics (Fig. 5a-c). For CPLs (Fig. 
5d), decreases are predominant in northern China, especially in northern Northeast China where the reductions can be more than 20 days. Whereas in the eastern Qinghai-Tibet Plateau and parts of Yungui Plateau, CPLs have increased by 5 to more than 20 days. As a result, from 1961-1990 to 1987-2016, 21 stations in nothern Northeast

China and the eastern Inner Mongolia Plateau have become no longer suitable for 'sunbird' tourism, along with

9 newly-added suitable stations in the eastern Qinghai-Tibet Plateau and Yungui Plateau (Fig. 3b).
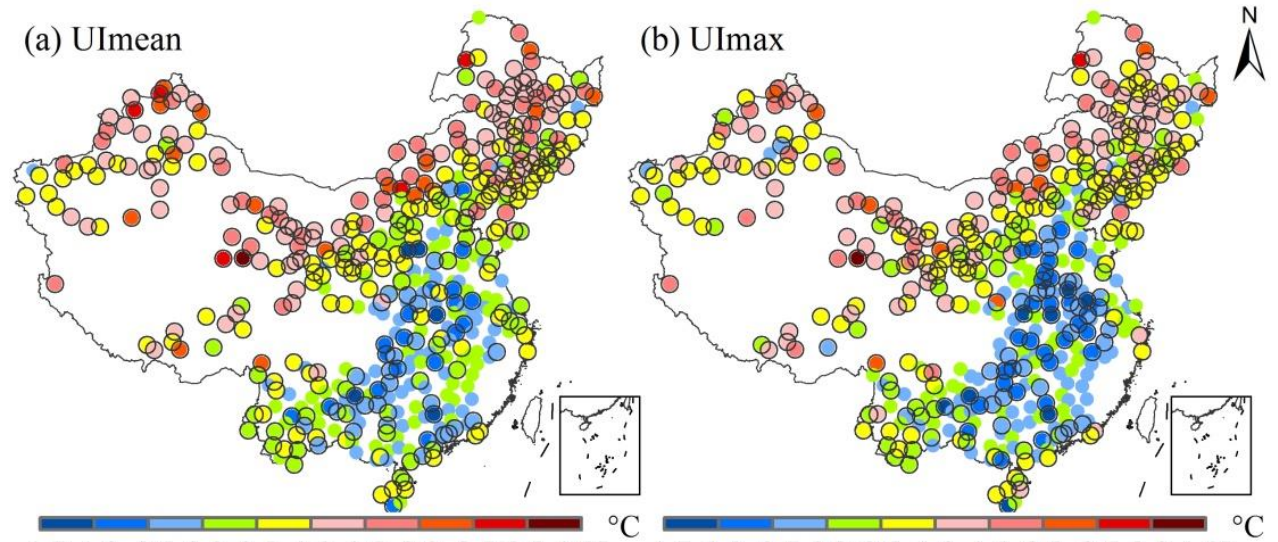

$\begin{array}{lllllllllll}-1.7 & -1.0 & -0.5 & 0.0 & 0.5 & 1.0 & 1.5 & 2.0 & 2.5 & 3.0 & 4.65\end{array}$

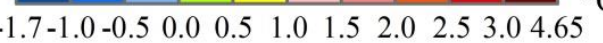

(c) UImin

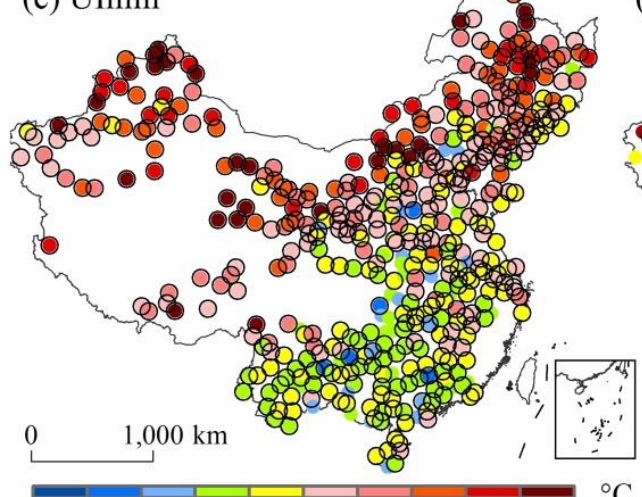

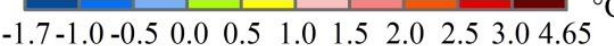

(d) CPL

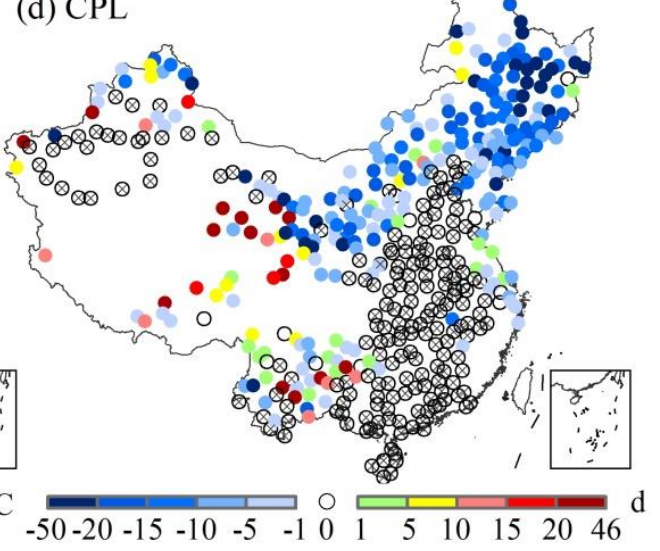

Fig. 5 Changes in summer average UImean (a), UImax (b) and UImin (c), and CPL (d) from 1961-1990 to 19872016; significant changes (at the 0.01 level) in UTCI values are marked by a solid circle; circles with a cross mark inside in (d) refer to stations without comfortable days in summer during both periods.

In addition, thermal conditions between both periods were compared for each ten-day interval. Figure 6 extracts stations with category changes (from or to "comfortable", "hot" or others) from the national total. Yet, the analyses here treat thermally suitable stations (Fig. 3a) as the overall sample. Amongst them, the numbers of stations with 
improved (others to comfortable, or hot to others) and deteriorated (comfortable to others, or others to hot) thermal conditions, referred as $\mathrm{N}_{\mathrm{i}}$ and $\mathrm{N}_{\mathrm{d}}$ respectively, were calculated for each ten-day interval in different regions (Table 2). This treatment aims to target the potential 'sunbird' tourism destinations, and help them with adaptations to climate change. In northern Northeast China, $\mathrm{N}_{\mathrm{i}}$ ranges from 4 to 10 (out of 16 stations in total) from the third ten-day interval of June to the first of August, corresponding to a more than 20 days reduction in CPL (Fig. 5d). Eastern Inner Mongolia Plateau, out of 16 stations, shows 9 and 7 of $\mathrm{N}_{\mathrm{i}}$ in the first and second tenday intervals of June, and 3 to 7 of $\mathrm{N}_{\mathrm{d}}$ from the first ten-day interval of July to the first of August, which combined make the comfortable period shift to an earlier time period. The Eastern Qinghai-Tibet Plateau has clearly benefited from the warming tendency, with $\mathrm{N}_{\mathrm{i}}$ of 6 to 8 (out of 28 stations) in June. Nevertheless, the hottest period (July and early August) has seen aggravated heat stress nationwide, and summer heat in southeastern China and southern Xinjiang has arrived earlier in June, possibly indicating both an increase in volume and a wider timespan for heat-escape travelling demand. 

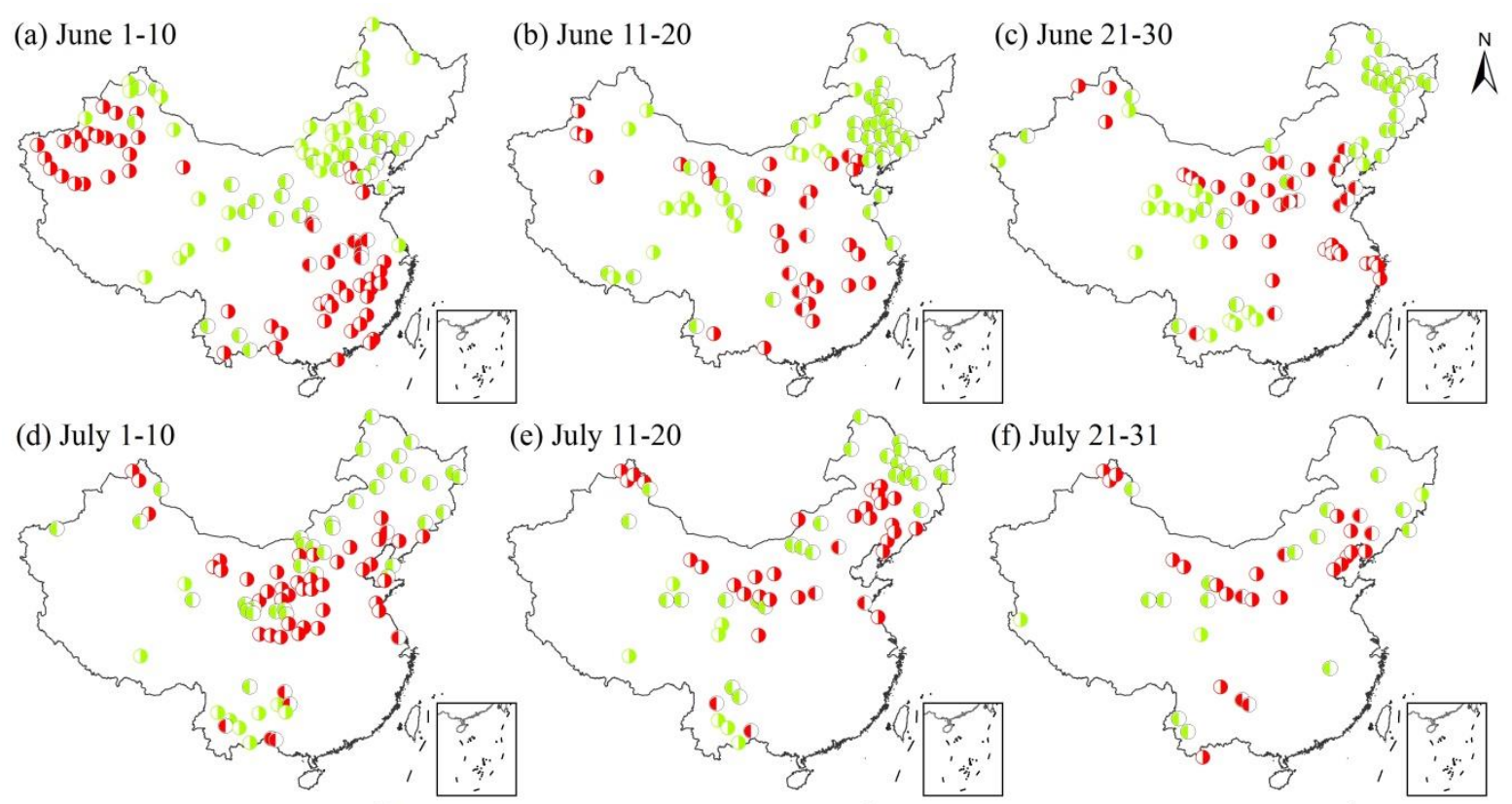

(e) July 11-20

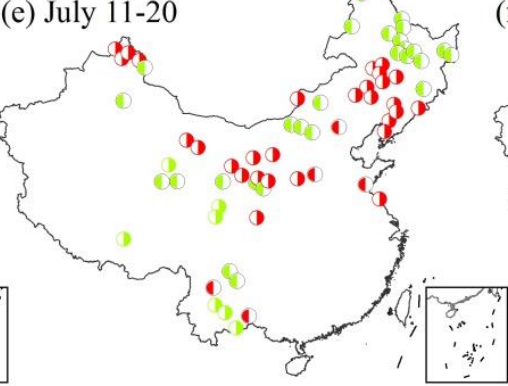

(g) August 1-10

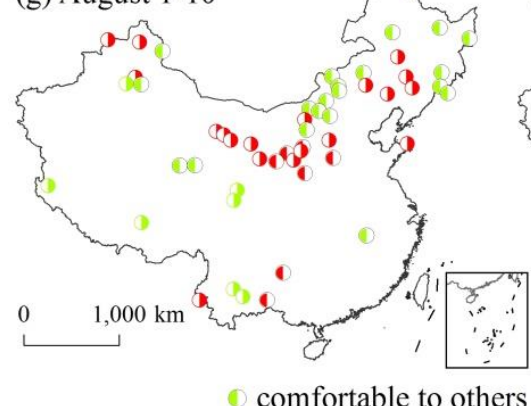

(h) August 11-20 (f) July 21-31

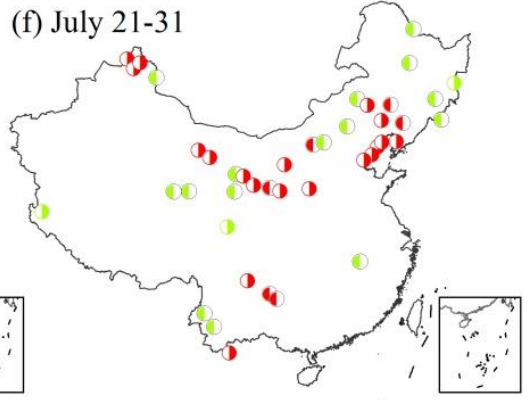

(i) August 21-31

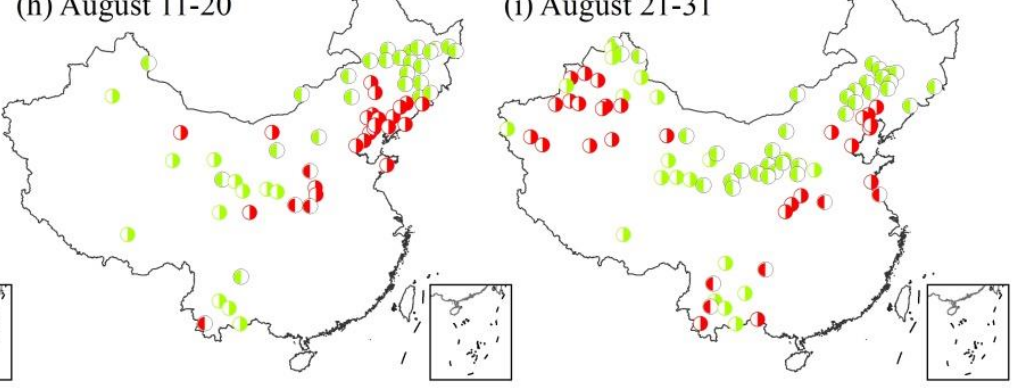

others to hot others to comfortable hot to others

Fig. 6 Changes in thermal conditions for each ten-day interval of summer from 1961-1990 to 1987-2016; only stations with category changes are displayed.

Table 2 The number of stations ${ }^{1}$ with improved and deteriorated thermal conditions from 1961-1990 to 1987-

2016 for each ten-day interval in different regions

\begin{tabular}{|c|c|c|c|c|c|c|c|}
\hline & & Northern & Eastern & Inner & Northern & Eastern Qinghai- & Yungui \\
\hline & & Northeast & Mongolia & & Xinjiang & Tibet Plateau & Plateau \\
\hline & & China & Plateau & & Province & & \\
\hline \multirow[t]{2}{*}{ Jun $1-10$} & $\mathrm{~N}_{\mathrm{i}}^{3}$ & $2\left(12.5 \%{ }^{2}\right)$ & $9(56.3 \%)$ & & $5(55.6 \%)$ & $6(21.4 \%)$ & - \\
\hline & $\mathrm{N}_{\mathrm{d}}^{3}$ & - & - & & - & - & - \\
\hline
\end{tabular}




\begin{tabular}{|c|c|c|c|c|c|c|}
\hline Jun 11-20 & $\mathrm{N}_{\mathrm{i}}$ & - & $7(43.8 \%)$ & $1(11.1 \%)$ & $8(28.6 \%)$ & - \\
\hline \multirow{3}{*}{ Jun 21-30 } & $\mathrm{N}_{\mathrm{d}}$ & - & - & - & $2(7.1 \%)$ & - \\
\hline & $\mathrm{N}_{\mathrm{i}}$ & - & - & $1(11.1 \%)$ & $8(28.6 \%)$ & - \\
\hline & $\mathrm{N}_{\mathrm{d}}$ & $8(50 \%)$ & $2(12.5 \%)$ & $1(11.1 \%)$ & $1(3.6 \%)$ & - \\
\hline \multirow[t]{2}{*}{ Jul 1-10 } & $\mathrm{N}_{\mathrm{i}}$ & - & - & - & $1(3.6 \%)$ & $1(6.7 \%)$ \\
\hline & $\mathrm{N}_{\mathrm{d}}$ & $6(37.5 \%)$ & $7(43.8 \%)$ & $1(11.1 \%)$ & $1(3.6 \%)$ & - \\
\hline \multirow[t]{2}{*}{ Jul 11-20 } & $\mathrm{N}_{\mathrm{i}}$ & - & - & - & $1(3.6 \%)$ & - \\
\hline & $\mathrm{N}_{\mathrm{d}}$ & $10(62.5 \%)$ & $4(25 \%)$ & $1(11.1 \%)$ & $5(17.9 \%)$ & $2(13.3 \%)$ \\
\hline \multirow[t]{2}{*}{ Jul 21-31 } & $\mathrm{N}_{\mathrm{i}}$ & $1(6.3 \%)$ & - & - & - & - \\
\hline & $\mathrm{N}_{\mathrm{d}}$ & $4(25 \%)$ & $3(18.8 \%)$ & $1(11.1 \%)$ & $4(14.3 \%)$ & - \\
\hline \multirow[t]{2}{*}{ Aug 1-10 } & $\mathrm{N}_{\mathrm{i}}$ & - & - & $1(11.1 \%)$ & - & - \\
\hline & $\mathrm{N}_{\mathrm{d}}$ & $5(31.3 \%)$ & $6(37.5 \%)$ & $1(11.1 \%)$ & $2(7.1 \%)$ & - \\
\hline \multirow[t]{2}{*}{ Aug 11-20 } & $\mathrm{N}_{\mathrm{i}}$ & - & - & $1(11.1 \%)$ & $2(7.1 \%)$ & - \\
\hline & $\mathrm{N}_{\mathrm{d}}$ & $2(12.5 \%)$ & $1(6.3 \%)$ & $1(11.1 \%)$ & $1(3.6 \%)$ & $1(6.7 \%)$ \\
\hline \multirow[t]{2}{*}{ Aug 21-30 } & $\mathrm{N}_{\mathrm{i}}$ & - & - & $5(55.6 \%)$ & $5(17.9 \%)$ & - \\
\hline & $\mathrm{N}_{\mathrm{d}}$ & - & - & - & $1(3.6 \%)$ & - \\
\hline
\end{tabular}

${ }^{1}$ Stations thermally suitable for 'sunbird' tourism were treated as the overall sample

${ }^{2}$ Percentage of the overall sample

${ }^{3} \mathrm{~N}_{\mathrm{i}}$ and $\mathrm{N}_{\mathrm{d}}$ respectively refer to the number of stations with improved and deteriorated thermal conditions

Finally, more detailed analyses were performed at three stations, Heihe, Xilinhot, and Golmud (Fig. 7 and Table 3), which constitute representative tourism destinations in Northeast China, the Inner Mongolia Plateau and the Qinghai-Tibet Plateau respectively. They all show significant increases (at the 0.001 level) in UTCI whether for 
the mean, maximum or minimum values. UImax exceeds $38{ }^{\circ} \mathrm{C}$ (very strong or extreme heat stress) more frequently as well, especially in Heihe and Golmud, where the frequencies have more than tripled and quintupled from 1961-1990 to 1987-2016 (Table 3). CPL decreases sharply in Heihe by 34 days, which mainly takes place from middle June to early August. Xilinhot, in comparison, experiences losses in comfortable days from late June to middle August, but gains in early June, thus leading to a moderate overall decrease by 11 days. For Golmud, the temporal distribution of comfortable period has been dramatically altered, with comfortable days transferring from middle July-early August to the periods before and after. Since the benefits far outweigh the losses, the comfortable period substantially extends by 27 days. However, such great adjustment of comfortable period still poses a potential challenge for local tourism sector, as it may lead to associated changes in both tourist volume and travelling time, requiring corresponding adaptations of tourism management.

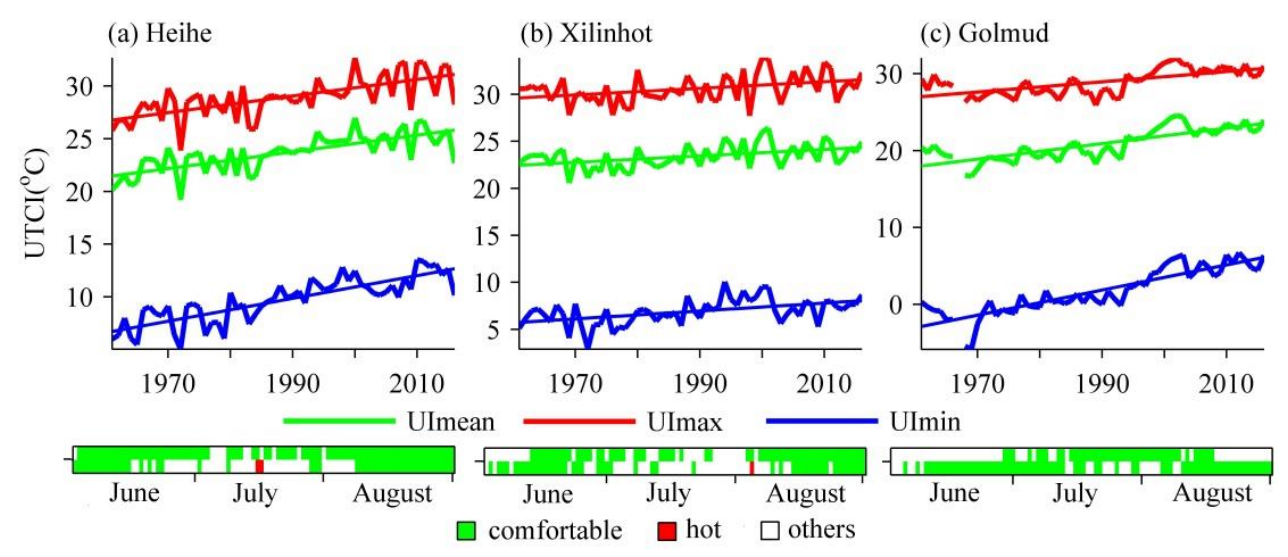

Fig. 7 Changes in summer average UImean, UImax and UImin (top), and comfortable periods (down) at Heihe (a), Xilinhot (b) and Golmud (c); in the top panel, straight lines indicate UTCI values' linear trends; in the lower panel, the upper and lower rows in the rectangles represent the periods 1961-1990 and 1987-2016 respectively, and each day is categorized as comfortable, hot or others.

Table 3 Changes in summer thermal conditions at Heihe, Xilinhot and Golmud 


\begin{tabular}{|c|c|c|c|c|c|c|c|}
\hline & UImean & UImax & UImin & 1961-1990 & 1987-2016 & 1961-1990 & 1987-2016 \\
\hline Heihe & 0.79 & 0.79 & 1.08 & 1.67 & 5.76 & 81 & 47 \\
\hline Xilinhot & 0.34 & 0.35 & 0.42 & 6.63 & 9.78 & 58 & 47 \\
\hline Golmud & 1.01 & 0.67 & 1.63 & 0.41 & 2.14 & 42 & 69 \\
\hline
\end{tabular}

${ }^{*}$ All trends are statistically significant at the 0.001 level

\section{Discussions}

\subsection{Comparison with other studies}

Two studies have been conducted to detect regions suitable for 'sunbird' tourism in China. Yang et al. (2016) quantified the suitability by integrating a set of environmental (thermal conditions, air quality, and forest cover) and socio-economic factors (current number of tourism destinations, tourism volume and revenue, local population, and transportation accessibility), and stratified the country into four levels from unsuitable to very suitable. Chen et al. (2015) not only identified the thermally suitable regions, but also performed cluster analysis on them based on the climate factors (temperature, humidity, wind speed, and radiation) that contribute to thermal properties.

However, both studies only used summer average UTCI to quantify thermal suitability, which is so coarse-grained that will inevitably lead to information loss and even misunderstanding. The most serious problem may lie in neglecting the diurnal variation of air temperature. High temperatures in the daytime, when tourists are typically exposed to outdoor environments (Lin and Matzarakis 2011), could be counteracted by low night-time temperatures, giving the illusion of comfortable conditions.

In comparison, the present study assesses thermal suitability in a much more comprehensive and detailed way by: (i) considering diurnal climate variation through the use of both maximum and minimum UTCI values; (ii) taking into account the effects of UTCI frequencies in defining comfortable days; (iii) employing thresholds on both the 
total and consecutive number of comfortable days to determine regions suitable for 'sunbird' tourism. The results are expected to be more accurate and robust.

The overall distributions of thermally suitable regions are similar between the present and previous studies. But, there still exist some differences. Southern Northeast China and coastal areas of the Bohai Sea are suitable, as revealed in their studies but not in ours until the criteria are relaxed to 20 comfortable days in total and 15 consecutive days (based on applying all combinations of 50, 40, 30, and 20 days in total, and 20, 15, and 10 days consecutively (not shown in figure)). Yang et al. (2016) also identified scattered suitable regions over southeast China where the CPLs, however, are mostly zero according to Figure 2d. In addition, the method based on summer averages of thermal indices is unable to inform tourists which area is comfortable during which period. We, for the first time to our knowledge, define comfortable calendar days.

\subsection{Implications for tourism development}

This study has identified potential locations thermally suitable for 'sunbird' tourism, and can inform tourists which area is comfortable during which period. This information is crucial for tourists planning their travels. Nevertheless, we acknowledge that various factors in addition to climate affect the tourism potential of a location, such as the local culture, economy, and transportation accessibility (Andrades and Dimanche 2017). Even the climate suitability should be evaluated through multiple aspects, including precipitation, barometric pressure, UV radiation, atmospheric oxygen, air pollution, etc. (de Freitas et al. 2008; Gómez Martín 2005; Mieczkowski 1985; Tang et al. 2012). For instance, low atmospheric oxygen and intense UV radiation, despite desirable thermal conditions, may make the climate in the high altitudes of the Qinghai-Tibet Plateau not favourable for tourism activities (Tang et al. 2012).

Changes in thermal conditions will improve or reduce the attractiveness of current tourism destinations. The comfortable periods can be lengthened, shortened, and/or temporally shifted. This is reasonably expected to affect 
tourists' choices in terms of both destinations and travelling time, since people tend to purchase climates that suit their holiday plans, instead of changing their vacation activities (Lise and Tol 2002). Considering the flexibility they have in choosing when and where to travel, tourists are speculated not to care much about climate change (Lise and Tol 2002). However, this may actually less be the case, since people's vacations are closely tied to national and school holidays (Ryan et al. 2017). Few people have the freedom to choose whenever they want to take a holiday. This conflict between variable climate and fixed holiday arrangements will increase tourists' vulnerability to climate change to some extent. Besides, travelling activities are usually driven by multiple motivations (Nicholson and Pearce 2001). Escaping the summer heat and enjoying the prairie landscape may both play a role in the decision to travel to the Inner Mongolia Plateau. The diversity of attractions in tourism destinations makes it difficult for different destinations to be substitutable for each other. Therefore, choosing another destination may sometimes involve a compromise by giving up one or two attractions. Especially in the hottest part of July and early August, tourists may be subject to more limited options in terms of both travelling time and destinations, due to intensifying heat stress nationwide. This could result in tourist overcrowding in a few destinations as well.

Changes in thermal conditions and tourists' choices require corresponding adaptations of tourism operators. Compared with tourists, tourism operators are less flexible especially at destinations with a large fixed input on infrastructure such as hotels and resorts (Nicholls and Amelung 2008). The variable climate and fast-changing tourism industry result in a short payback period for those investments, which comes with a high risk. Destinations with deteriorating thermal conditions, generally due to the warming trend, will face great challenges, even if these adverse impacts have not been observed, possibly due to a time lag in tourists' response to climate change (Moreno 2010). A long-term viewpoint is necessary, especially considering that this warming tendency is expected to continue into the future (Leng et al. 2016; Wang and Chen 2014; Zhang et al. 2006). The possible adaptations 
may include developing alternative tourism attractions, making better use of mountain climate resources, improving cooling equipment, building additional outdoor shelters, and optimizing emergency systems to cope with heat stress-related morbidity (Ge et al. 2017). Destinations with improved thermal conditions, such as those in the eastern Qinghai-Tibet Plateau, should make this advantage widely known through strategic advertising, develop comfortable climate-based products, and improve local accommodation and transportation capacities to cope with possible increases in tourist arrivals ( $\mathrm{Li}$ and $\mathrm{Chi}$ 2014). Meanwhile, changes in the temporal distribution of comfortable periods, as seen in the case of Golmud, also ask for adjustment in management resources. More human and financial resources should be transferred to the traditional shoulder season which may have become increasingly attractive (Amelung and Viner 2006; Nicholls and Amelung 2008) .

\section{Conclusion}

Using daily meteorological observations (1961-2016) and the UTCI, this study identified regions thermally suitable for 'sunbird' tourism and their comfortable periods in China, namely northern Northeast China in June and the last two ten-day intervals of August, eastern Inner Mongolia Plateau from the second ten-day interval of June to August, and northern Xinjiang Province, eastern Qinghai-Tibet Plateau and Yungui Plateau throughout summer. We also compared thermal conditions between two sub-periods, 1961-1990 and 1987-2016, for both the summer as a whole and each ten-day interval. Northern Northeast China and eastern Inner Mongolia Plateau have been adversely impacted, with comfortable period length generally reduced by 5 to more than 20 days, and 21 stations no longer suitable for 'sunbird' tourism. Eastern Qinghai-Tibet Plateau has clearly benefited from recent warming with a 5 to more than 20 days extension in comfortable periods and 7 newly-added suitable stations; however, the dramatic adjustment of comfortable periods with respect to temporal distribution still poses a potential challenge for tourism management. 
Climate model simulations have revealed that both the mean temperature and hot extremes in China will increase in the future (Jiang et al. 2012; Li et al. 2011; Wang and Chen 2014; Zhang et al. 2006). Extreme hot summers (JJA mean temperature higher than 90th percentile of the 1971-2000 climatology) will become the norm for approximately $97 \%$ of the country's land area under a $+2.5^{\circ} \mathrm{C}$ global warming, which is much greater than the global average (Leng et al. 2016). The warming tendency is especially manifested on the Tibetan Plateau and in Southwest China (Jiang et al. 2012), which may further improve the thermal condition over these regions. However, continuously increasing summertime heat stress and more and more unpleasant thermal conditions can be expected in the remaining areas. Along with that is the increasing gap between growing demand and limited supply for 'sunbird' tourism, and a series of associated problems, including tourist overcrowding, bad travel experiences, greater pressure on ecologically sensitive regions like Tibet Plateau, etc.

\section{Reference}

Amelung B, Moreno A (2012) Costing the impact of climate change on tourism in Europe: results of the PESETA project. Clim Chang 112:83-100. doi:10.1007/s10584-011-0341-0

Amelung B, Nicholls S, Viner D (2007) Implications of Global Climate Change for Tourism Flows and Seasonality. J Travel Res 45:285-296. doi:10.1177/0047287506295937

Amelung B, Viner D (2006) Mediterranean Tourism: Exploring the Future with the Tourism Climatic Index. J Sustain Tour 14:349-366. doi:10.2167/jost549.0

Andrades L, Dimanche F (2017) Destination competitiveness and tourism development in Russia: Issues and challenges. Tourism Management 62:360-376. https://doi.org/10.1016/j.tourman.2017.05.008

Batista RJR, Gonçalves FLT, da Rocha RP (2016) Present climate and future projections of the thermal comfort index for the metropolitan region of São Paulo, Brazil. Clim Chang 137:439-454. doi:10.1007/s10584016-1690-5

Błazejczyk K (2004) Radiation balance in man in various meteorological and geographical conditions. Geographia Polonica 77:63-76

Błażejczyk K, Epstein Y, Jendritzky G, Staiger H, Tinz B (2012) Comparison of UTCI to selected thermal indices. Int J Biometeorol 56:515-535. doi:10.1007/s00484-011-0453-2 
Bröde P, Fiala D, Błażejczyk K, Holmér I, Jendritzky G, Kampmann B, Tinz B, Havenith G (2012) Deriving the operational procedure for the Universal Thermal Climate Index (UTCI). Int J Biometeorol 56:481-494. doi:10.1007/s00484-011-0454-1

Chen H, Yan Y, Yue S, Meng B, Wang X (2015) Types of summer comfortable climate in China and their temporal and spatial distribution. Progress in Geography 34:175-184

Cheung CSC, Hart MA (2014) Climate change and thermal comfort in Hong Kong. Int J Biometeorol 58:137148. doi:10.1007/s00484-012-0608-9

de Freitas CR (1990) Recreation climate assessment. Int J Climatol 10:89-103. doi:10.1002/joc.3370100110

Douglas VH (1977) Percent of Possible Sunshine and the Total Cloud Cover. Mon Weather Rev 105:648-652. doi:10.1175/1520-0493(1977)105<0648:popsat>2.0.co;2

Essa KS, Etman SM (2004) On the relation between cloud cover amount and sunshine duration. Meteorol Atmos Phys 87:235-240. doi:10.1007/s00703-003-0046-7

Fiala D, Havenith G, Bröde P, Kampmann B, Jendritzky G (2012) UTCI-Fiala multi-node model of human heat transfer and temperature regulation. Int J Biometeorol 56:429-441. doi:10.1007/s00484-011-0424-7

Fiala D, Lomas KJ, Stohrer M (2001) Computer prediction of human thermoregulatory and temperature responses to a wide range of environmental conditions. Int J Biometeorol 45:143-159. doi:10.1007/s004840100099

Ge Q, Kong Q, Xi J, Zheng J (2017) Application of UTCI in China from tourism perspective. Theor Appl Climatol 128:551-561. doi:10.1007/s00704-016-1731-z

Giannakopoulos C, Kostopoulou E, Varotsos KV, Tziotziou K, Plitharas A (2011) An integrated assessment of climate change impacts for Greece in the near future. Reg Environ Change 11:829-843. doi:10.1007/s10113-011-0219-8

Gómez Martín MB (2005) Weather, climate and tourism a geographical perspective. Ann Tourism Res 32:571591. https://doi.org/10.1016/j.annals.2004.08.004

Grillakis MG, Koutroulis AG, Tsanis IK (2016) The $2{ }^{\circ} \mathrm{C}$ global warming effect on summer European tourism through different indices. Int J Biometeorol 60:1205-1215. doi:10.1007/s00484-015-1115-6

Hamilton JM, Maddison DJ, Tol RSJ (2005) Climate change and international tourism: A simulation study. Glob Environ Change 15:253-266. https://doi.org/10.1016/j.gloenvcha.2004.12.009

Hanson CE, Palutikof JP, Dlugolecki A, Giannakopoulos C (2006) Bridging the gap between science and the stakeholder: the case of climate change research. Clim Res 31:121-133. doi:10.3354/cr031121

Havenith G, Fiala D, Błazejczyk K, Richards M, Bröde P, Holmér I, Rintamaki H, Benshabat Y, Jendritzky G (2012) The UTCI-clothing model. Int J Biometeorol 56:461-470. doi:10.1007/s00484-011-0451-4 
Jendritzky G, de Dear R, Havenith G (2012) UTCI-Why another thermal index? Int J Biometeorol 56:421428. doi:10.1007/s00484-011-0513-7

Jiang Z, Song J, Li L, Chen W, Wang Z, Wang J (2012) Extreme climate events in China: IPCC-AR4 model evaluation and projection. Clim Chang 110:385-401. doi:10.1007/s10584-011-0090-0

Lemesios G, Giannakopoulos C, Papadaskalopoulou C, Karali A, Varotsos KV, Moustakas K, Malamis D, Zachariou-Dodou M, Petrakis M, Loizidou M (2016) Future heat-related climate change impacts on tourism industry in Cyprus. Reg Environ Change 16:1915-1927. doi:10.1007/s10113-016-0997-0

Leng G, Tang Q, Huang S, Zhang X (2016) Extreme hot summers in China in the CMIP5 climate models. Clim Chang 135:669-681. doi:10.1007/s10584-015-1576-y

Li R, Chi X (2014) Thermal comfort and tourism climate changes in the Qinghai-Tibet Plateau in the last 50 years. Theor Appl Climatol 117:613-624. doi:10.1007/s00704-013-1027-5

Lin T-P, Matzarakis A (2011) Tourism climate information based on human thermal perception in Taiwan and Eastern China. Tourism Management 32:492-500. http://doi.org/10.1016/j.tourman.2010.03.017

Lise W, Tol RSJ (2002) Impact of Climate on Tourist Demand. Clim Chang 55:429-449. doi:10.1023/a:1020728021446

lqbal M (1983) An introduction to solar radiation. Academic Press, New York

Mieczkowski Z (1985) The tourism climatic index: a method of evaluating world climates for tourism. The Canadian Geographer 29:220-233. doi:10.1111/j.1541-0064.1985.tb00365.x

Nicholls S, Amelung B (2008) Climate change and tourism in Northwestern Europe: impacts and adaptation. Tourism Analysis 13:21-31. doi:10.3727/108354208784548724

Nicholson RE, Pearce DG (2001) Why do people attend events: a comparative analysis of visitor motivations at four South Island events. J Travel Res 39:449-460. https://doi.org/10.1177/004728750103900412

Rensheng C, Shihua L, Ersi K, Jianping Y, Xibin J (2006) Estimating daily global radiation using two types of revised models in China. Energ Convers Manage 47:865-878. http://doi.org/10.1016/j.enconman.2005.06.015

Rutty M, Scott D (2010) Will the Mediterranean Become “Too Hot” for Tourism? A Reassessment. Tourism and Hospitality Planning \& Development 7:267-281. doi:10.1080/1479053X.2010.502386

Scott D, McBoyle G, Schwartzentruber M (2004) Climate change and the distribution of climatic resources for tourism in North America. Clim Res 27:105-117. doi:10.3354/cr027105

Tang C, Zhong L, Kristen M, Cheng S (2012) A comprehensive evaluation of tourism climate suitability in Qinghai Province, China. J MT SCI-ENGL 9:403-413. doi:10.1007/s11629-009-2161-5

Wang L, Chen W (2014) A CMIP5 multimodel projection of future temperature, precipitation, and climatological drought in China. Int J Climatol 34:2059-2078. doi:10.1002/joc.3822 
Wang S, Li W (2007) Climate of China. China Meteorological Press, Beijing

Yang J, Zhang Y, Xi J (2016) The comprehensive evaluation of suitability of summer tourism base in China.

Resources Science 38:2210-2220 